\title{
Cooking Behavior of Mixture Wood Chips Consisting of Different Species
}

\author{
Hiroshi Ougiya*2 \\ Pulp Sec., Pulp Production Dept., MPM OPERATION Co., Ltd. ${ }^{* 1}$ \\ Masatoshi Ishihuji \\ Technical Group, Technical Dept., MPM OPERATION Co., Ltd. ${ }^{* 1}$
}

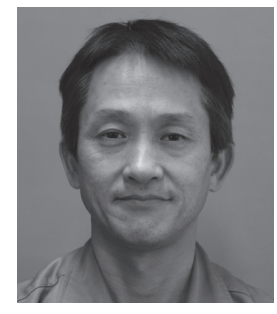

Hiroshi Ougiya

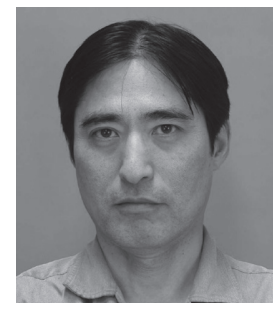

Masatoshi Ishihuji

\begin{abstract}
Optimization of chip mixture largely depends on chip quality such as pulp yield and digestibility. Chip of Eucalyptus globulus shows high pulp yield and easy digestibility compared with that of Acacia mangium. To study cooking behavior of Eucalyptus chip and Acacia chip individually, we separated them respectively with packing each chip into a metal basket and digested together. As a result of analysis of cooking behavior of each chip by experimental digestion, we confirm that behavior of chip mixture during digestion can be explained from average of digestibility of individual chips constituting the mixture. Kappa number and pulp yield of two species of chips were not affected by each other.
\end{abstract}

Keywords : chip mixture, digestibility, cooking behavior

\section{Introduction}

It seems feasible for a pulp mill located in the vicinity of planted woodland in Southeast Asia and South America to produce pulp from single afforested wood species. However in Japan, it is believed that many mills primarily use wood chip mixture of imported several wood spe$\operatorname{cies}^{1)}$. . Although there are several advantages of using wood chips from multiple resources such as lower chip cost and more stable supply, the main disadvantages of pulping mixed chips would be lower efficiency of production and operation. Due to the differences in the pulping characteristics such as pulp yield and bleachability, the optimum cooking conditions which depend upon wood

\footnotetext{
${ }^{* 1} 3$ Aomoriyachi, Kawaragi, Hachinohe-shi, Aomori 039-1161, Japan

${ }^{* 2}$ E-mail : ougiya_Hiroshi@mpm.co.jp
}

species and chip mixing ratio would not be the same with those of each wood chip. Therefore cooking mixed chips may lead to higher chemical consumption and lower pulp yield. In order to determine the optimum cooking conditions that would minimize loss in production and operation efficiency, it is of prime importance to evaluate chip qualities and cooking behavior of each wood species $^{1)-3)}$. Digestibility of various wood species such as Acacia mangium, Acacia auriculiformis, Eucalyptus diversicolor and Leucaena latisiliqua were investigated by, Setsu et al. ${ }^{5)}$, Inai et al. ${ }^{6)}$ and Usami et al. ${ }^{7)}$ respectively. Although cooking experiments of single wood species revealed cooking behavior and pulp yields, limited results have been reported on mixture of multiple wood species. Watanabe $^{4)}$ showed that adding $10 \%$ P. falcataria to Acacia mangium chips resulted in lower pulp yield at the same kappa number than Acacia mangium. Usami ${ }^{7)}$ stated that pulp qualities made from chip mixture of $50 \%$ 
Leucaena latisiliqua and $50 \%$ birch were equal to the arithmetic average of each wood species. The objective of our research was to achieve useful information in optimizing conditions for cooking multiple wood species by laboratory experiments. We investigated the effect of Acacia mangium chips that were difficult to cook when they were added as the admixture in Eucalyptus globulus chips that had excellent digestibility.

\section{Chilean E. globulus and Vietnamese A. mangium}

Digestibility of E. globulus imported from Chile and $A$. mangium from Vietnam was compared. Both of them are widely used for pulping in Japan. 18 lots from 7 Chilean E. globulus suppliers and 18 lots from 6 Vietnamese A. mangium suppliers were cooked by the methods described later. Fig. 1 shows the total pulp yield of unbleached pulps at 18.5 kappa number. It was found that E. globulus pulps had higher pulp yield with lower EA\% than A. mangium pulps. Average chip densities of 18 lots are shown in Fig. 2. E. globulus chips were found to have higher chip density in comparison with A. mangium. From these data, the optimum cooking conditions are estimated to differ so much between two wood species that chemical addition and productivity should be adjusted for each species. In pulp mills, separate cooking of different wood species is rarely practiced. Instead chips are mixed by the predetermined ratio and cooking mixed chips is widely performed. Laboratory experiments were carried out to find the effects of chip admixture on the digestibility.

\section{Experimental}

\section{1 Samples}

E. globulus chips were obtained from 12 years old afforested trees of ASTEX in Chile and A. mangium chips were prepared from 5-7 years old afforested trees of Chipexco in Vietnam. The wood chip samples were air dried under the same conditions and were screened separately with a laboratory pulpwood chips classifier. The under-sized pin chips and over-sized chips were rejected to obtain the middle fractions of $4.8-38.1 \mathrm{~mm}$. Table 1 shows wood chip densities. Density of A. mangium chips was lighter than E. globulus.

\subsection{Kraft cooking}

To study cooking behavior of Eucalyptus chips and Acacia chips individually, we separated them respectively

Table 1 Basic density of material chip

\begin{tabular}{l|c|c}
\hline & E. globulus & A. mangium \\
\hline Basic density $\quad \mathrm{kg} / \mathrm{m}^{3}$ & 519 & 448 \\
\hline
\end{tabular}

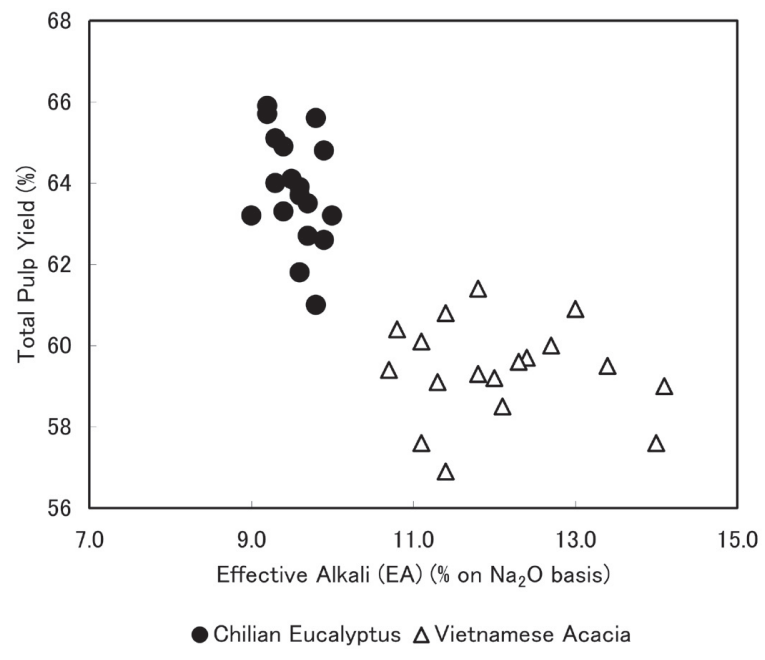

Fig. 1 Pulp yield of eucalyptus and acacia

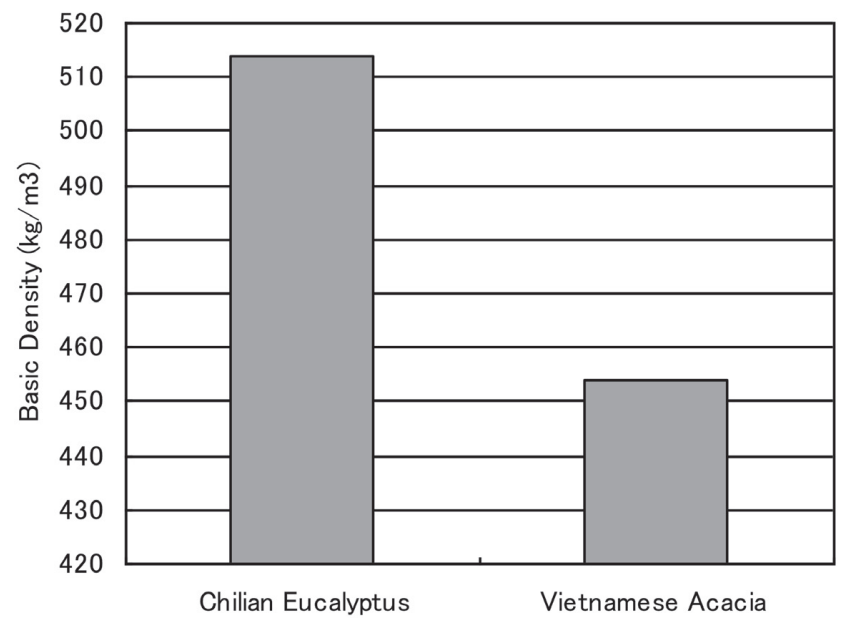

Fig. 2 Basic density of eucalyptus and acacia

with packing each chip into a metal basket and digested together. In other words, two baskets made of $1 \mathrm{~mm}$ opening wire were filled with E. globulus chips (abbreviated as $\left.\mathrm{EG}_{\text {mix }}\right)$ and A.mangium chips $\left(\mathrm{AM}_{\text {mix }}\right)$ respectively. The total chip weight was 400 bone dry gram, consisting of $80 \%$ E. globulus and $20 \%$ A. mangium. Two baskets were placed in a 4 liters experimental autoclave and immersed in the same cooking liquor as is shown in Fig. 3. Cooking conditions are given in Table 2. Different pulps that were produced in two separate baskets were evaluated about kappa number, pulp yield and brightness. As a reference, mixed chips (EG and AM), 100\% E. globulus chips $\left(\mathrm{EG}_{\text {individual }}\right)$ and $100 \%$ A. mangium chips $\left(\mathrm{AM}_{\text {individual }}\right)$ were cooked without using baskets.

\subsection{Evaluation}

Unbleached pulps were washed with water and measurements of total pulp yield (air dry pulp weight/bone dry chip weight, \%), kappa number and pulp brightness. 
Table 2 Laboratory cooking conditions

\begin{tabular}{lc|c}
\hline \multicolumn{1}{c|}{ Term } & Unit & \\
\hline Max. temperature & ${ }^{\circ} \mathrm{C}$ & 170 \\
Holding time at max. temp. & $\mathrm{min}$. & 43 \\
L/W ratio & $\mathrm{L} / \mathrm{kg}$ & 4.5 \\
Effective Alkali (EA) & $\%$ (on $\mathrm{Na}_{2} \mathrm{O}$ basis) & $9 \sim 16$ \\
Sulfidity & $\%$ (on $\mathrm{Na}_{2} \mathrm{O}$ basis) & 25 \\
\hline
\end{tabular}

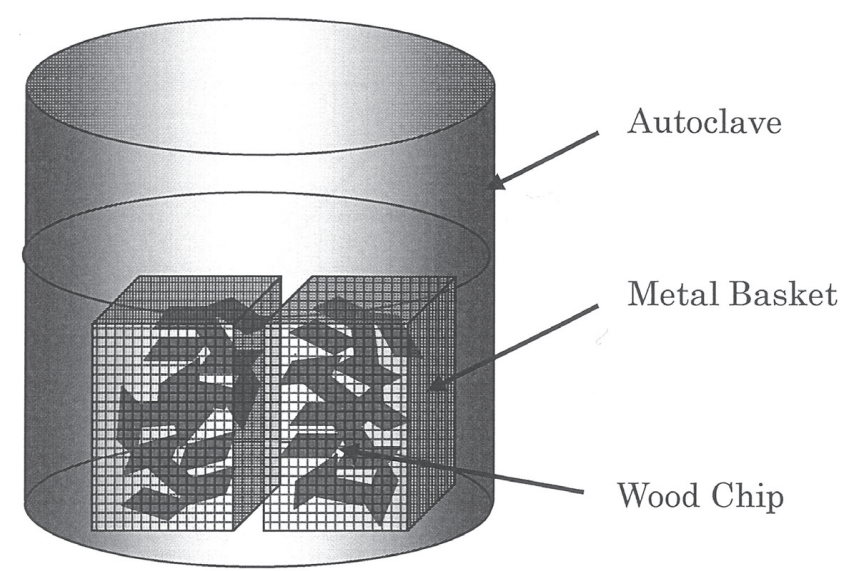

Fig. 3 Experimental cooking apparatus

\section{Results and Discussion}

\subsection{Kappa number of unbleached pulps}

The kappa number-effective alkali addition (EA\%) relationships are shown in Fig. 4. Compared at the same addition of EA\%, the A. mangium pulps had 2 times higher kappa number than the E. globulus pulps, indicating that $E$.globulus chips cooked well than A. mangium chips. The kappa number of mixed chips was between those of A. mangium and E. globulus, and coincided well with the arithmetical average of $80 \%$ E. globulus and $20 \%$ A. mangi$u m$. Based on the results presented above, one may draw a conclusion that the kappa number of mixed chips (EG and AM) can be estimated by the mixing ratio and the kappa number of each wood species. The curve plotted between the kappa number and EA\% of E. globulus using the basket $\left(\mathrm{EG}_{\text {mix }}\right)$ fitted well with the curve obtained from individual cooking without using the basket $\left(\mathrm{EG}_{\text {indi- }}\right.$ vidual). This was observed too in A. mangium pulps with $\left(\mathrm{AM}_{\text {mix }}\right)$ and without using the basket $\left(\mathrm{AM}_{\text {individual }}\right)$, suggesting that delignification reaction of the wood chips was not affected by the presence of other wood chips. Before the experiments we had anticipated that the alkali consumption rate of the wood chips might affect the delignification rate of other wood chips due to the different digestibility. But this was not true in our experiments. Further study is necessary to verify whether our hypothesis is applicable to different wood species under different cooking conditions.

\subsection{Pulp yield}

The total pulp yield-kappa number relationships of $E$. globulus and A. mangium chips in Fig. 5 were obtained by changing the alkali concentration of cooking liquor. Similar to the relationships of kappa number-EA\%, wood chips were found to differ in pulp yield between E. globulus and A. mangium. The curve plotted between the total pulp yield and kappa number using the basket coincided well with the curve obtained from individual cooking without using the basket. In real pulping operation in a mill, kappa number is selected as a set point of the kraft cooking operation. When the target kappa number is 15 , required EA\% is $10 \%$ for E. globulus chips, $15 \%$ for $A$. mangium chips and $12-12.5 \%$ for chip mixture as are shown in Fig. 4. The kappa number of the mixed pulp was 15, while that of E. globulus and A. mangium pulps contained in the mixed pulps was 12 and 25 respectively.

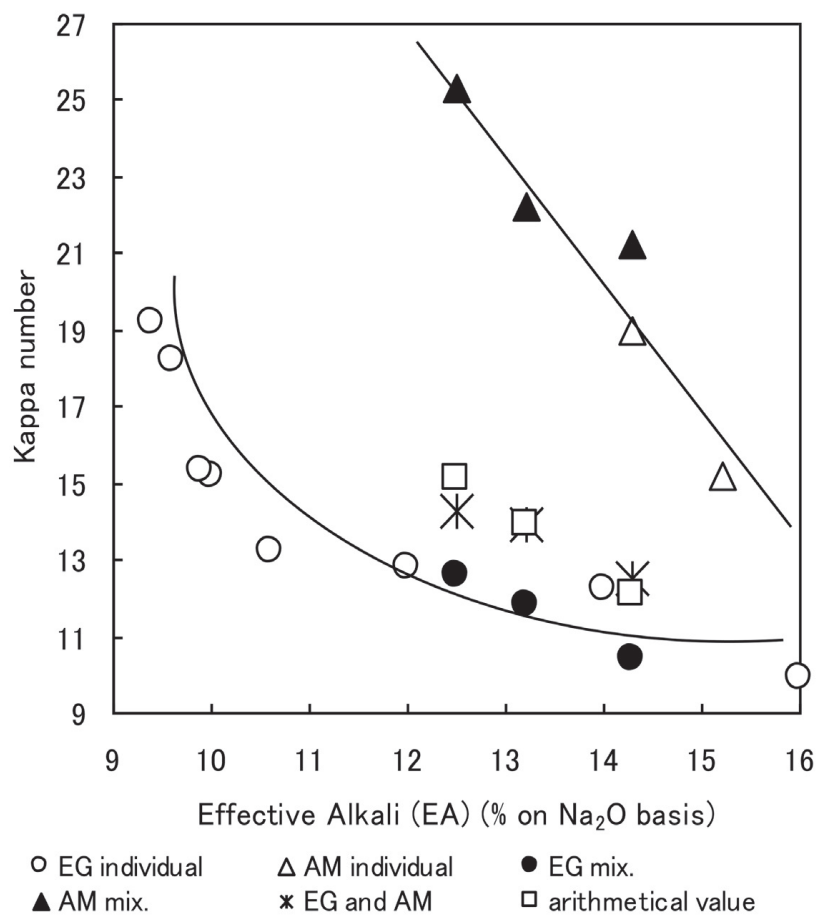

Fig. 4 Kappa number of mixture of E. globulus (EG) and A.mangium (AM) 


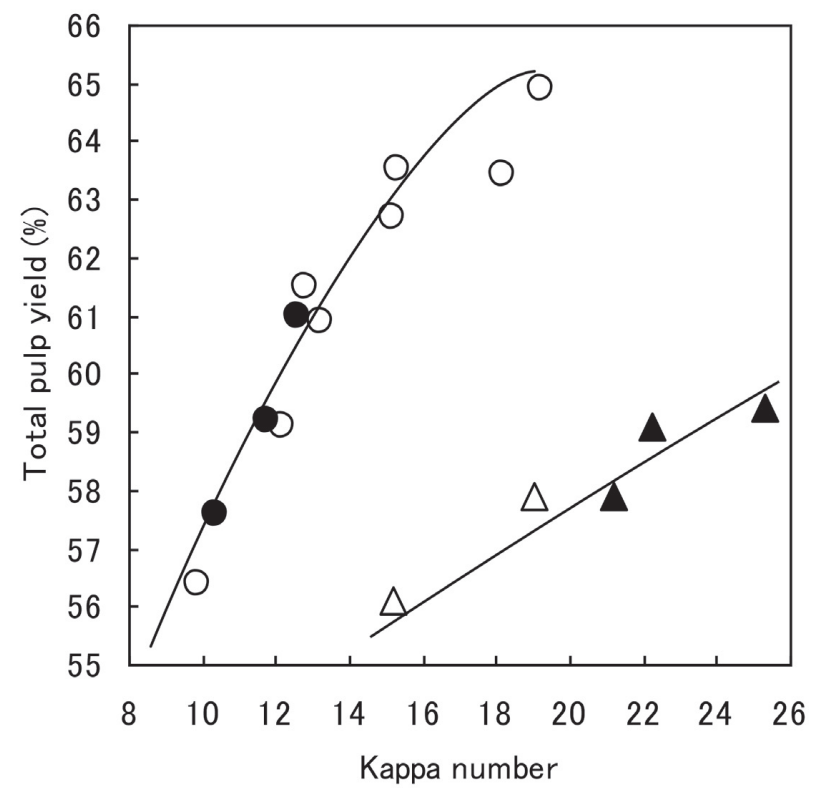

$O E G$ individual $\triangle A M$ individual $\bullet E G$ mix. $\triangle A M$ mix.

Fig. 5 Pulp yield of mixture of E. globulus (EG) and A. mangium (AM)

Fig. 5 shows that the total pulp yield at 15 kappa number was $63 \%$ for E. globulus, $56 \%$ for A. mangium and 59 $\%$ for mixed chips. Accordingly addition of $20 \%$ A. mangium chips to E. glubulus chips was estimated to decrease the pulp yield by $4 \%$ in comparison with $100 \%$ E. globulus. It was due to the different digestibility $:$ E. globulus chips were over-cooked while A. mangium chips were under-cooked. Watanabe ${ }^{4)}$ showed that adding 10\% P. falcataria to Acacia mangium chips resulted in lower pulp yield at the same kappa number than Acacia mangium.

\subsection{Brightness}

Fig. 6 shows the brightness of unbleached pulps-kappa number relationships of E. globulus and A. mangium. A. mangium pulps resulted in linear relationships while $E$. glubulus pulps had inflection points around at the kappa number of 12-14. Plots of brightness and kappa number that were obtained by separate cooking with the baskets and individual cooking without the baskets got on the same curve.

\section{Conclusion}

Under the conditions studied, the results showed that kraft pulping of mixed chips resulted in pulps with the arithmetic average of kappa number, pulp yield and brightness of each wood species. It was found that digestibility of the wood chips was not affected by the

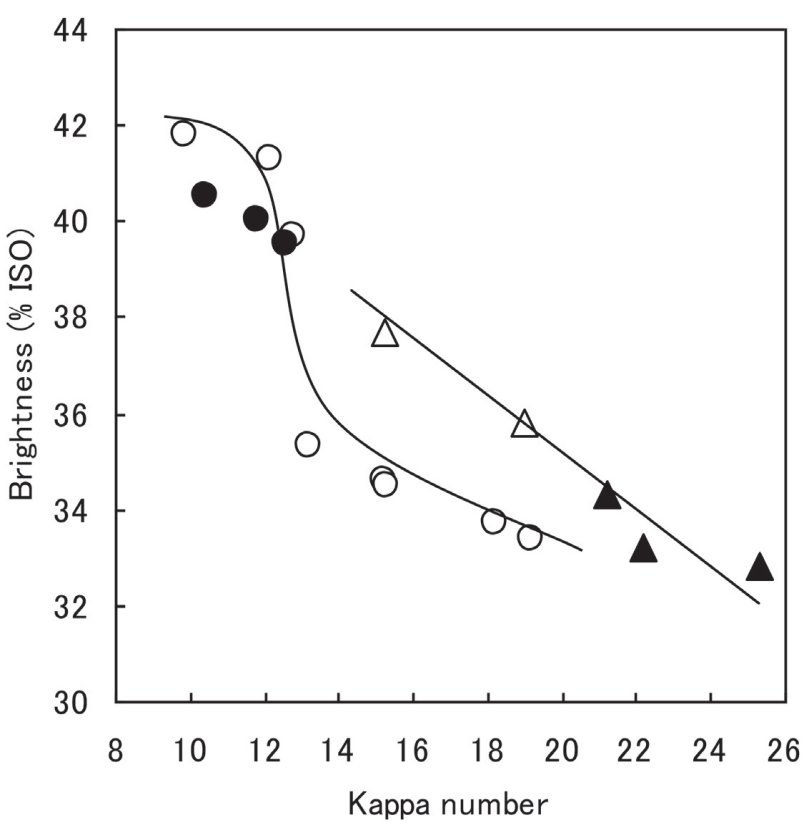

$O E G$ individual $\triangle A M$ individual $-E G$ mix. $\triangle A M$ mix.

Fig. 6 Brightness of mixture of E. globulus (EG) and A. mangium (AM)

presence of other wood species. This is import when we use mixed chips with different cooking behavior. We can estimate the pulp yield and kappa number of mixed chips from the digestibility of each wood species and optimize the cooking conditions as well as the chip mixing ratio to minimize the variation of production and operation efficiency. Further study is necessary to verify whether the concluding remarks we obtained from $E$. globulus and A. mangium experiments are applicable to different wood species under different pulping conditions.

\section{References}

1) Suzumi R. : JAPAN TAPPI J. 60 (7) 1038-1042 (2006)

2) Homma M., et al. : JAPAN TAPPI J. 63 (3) 307-312 (2009)

3) Uchida Y. : JAPAN TAPPI J. 60 (7) 1050-1053 (2006)

4) Watanabe K., et al. : JAPAN TAPPI J. 58 (8) 10971103 (2004)

5) Xue G., et al. : JAPAN TAPPI J. 55 (3) 366-372 (2001)

6) Inai H., et al. : JAPAN TAPPI J. 35 (10) 895-912 (1981)

7) Usami K., et al. : JAPAN TAPPI J. 34 (8) 576-581 (1980) 